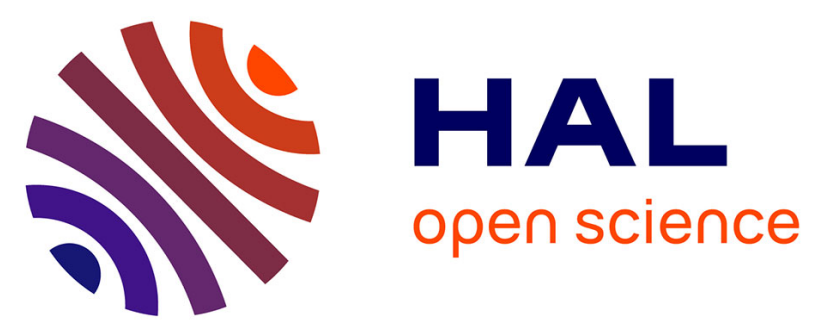

\title{
Analytical and experimental investigation of the delamination during drilling of composite structures with core drill made of diamond grits: X-ray tomography analysis
}

Jamel Saoudi, Redouane Zitoune, Suhasini Gururaja, Mehdi Salem, Salah Mezleni

\section{To cite this version:}

Jamel Saoudi, Redouane Zitoune, Suhasini Gururaja, Mehdi Salem, Salah Mezleni. Analytical and experimental investigation of the delamination during drilling of composite structures with core drill made of diamond grits: X-ray tomography analysis. Journal of Composite Materials, 2018, 52 (10), p.1281-1294. 10.1177/0021998317724591 . hal-01685185

\section{HAL Id: hal-01685185 \\ https://imt-mines-albi.hal.science/hal-01685185}

Submitted on 17 Nov 2020

HAL is a multi-disciplinary open access archive for the deposit and dissemination of scientific research documents, whether they are published or not. The documents may come from teaching and research institutions in France or abroad, or from public or private research centers.
L'archive ouverte pluridisciplinaire $\mathbf{H A L}$, est destinée au dépôt et à la diffusion de documents scientifiques de niveau recherche, publiés ou non, émanant des établissements d'enseignement et de recherche français ou étrangers, des laboratoires publics ou privés. 


\title{
Analytical and experimental investigation of the delamination during drilling of composite structures with core drill made of diamond grits: X-ray tomography analysis
}

\author{
Jamel Saoudi',2, Redouane Zitoune', Suhasini Gururaja ${ }^{3}$, \\ Mehdi Salem' and Salah Mezleni'
}

\begin{abstract}
Among the various forms of material damage, exit-ply delamination has been identified as one of the most deleterious damage processes associated with drilling fibre-reinforced plastics. The thrust force has been cited as the primary cause for drilling-induced exit-ply delamination. Only one analytical model for the prediction of the critical thrust force responsible for delamination using core drills can be found in the literature. In this study, a realistic model to predict critical thrust force responsible for drilling-induced exit-ply delamination in a multi-directional carbon fibre-reinforced plastic laminate with core drill has been proposed. A comparison between the proposed model, literature model as well as the experimental tests conducted during punching tests is presented. The proposed model is found to correlate well with experimental punching tests. In fact, the maximum relative errors recorded between the experimental values of the critical thrust force and the measured values are around 15\%. Micro-tomography experiments have also been conducted that capture the drilling-induced damage in multi-directional carbon fibre-reinforced plastics in great detail. The $X$-ray images highlight the difficulty in controlling the thickness of the uncut plies located under the core drill during punching tests that can be attributed to some deviations in predictions of critical thrust force. Postmortem examination of the blind holes after punching tests also confirms the presence of a net delamination near the vicinity of the nominal diameter of the core drill, which correlates well to the hypothesis of the analytical model.
\end{abstract}

\section{Keywords}

Modeling, exit-ply delamination, fracture mechanic, drilling, composite, core drill, X-ray tomography

\section{Introduction}

Nowadays, composite materials are being used widely compared to metallic materials ranging from aerospace to sport goods industries. ${ }^{1-3}$ The heterogeneous and anisotropic behavior of carbon fibre-reinforced plastic (CFRP) materials poses real problems in their machining. In the aerospace industry, conventional drilling process is the most commonly applied method for generating holes and then for riveting and fastening structural assembly. ${ }^{4,5}$ However, this process of machining for composite materials has always been a challenge due to a host of difficulties. The mechanism of machining for composite materials has been recognized as a process different from that of homogeneous and isotropic materials. ${ }^{6,7}$ Moreover, several undesirable forms of damage (such as matrix cracking, mechanical and thermal degradation of the matrix, delamination and fibre breakage) induced by drilling drastically reduce the maximum failure stress and the endurance

'Institut Clément Ader (ICA), UMR-CNRS 53 I2, "INSA, UPS, Mines Albi, ISAE", France

${ }^{2}$ Ecole Nationale d'Ingénieurs de Monastir, Tunisia

${ }^{3}$ Aerospace Engineering, Indian Institute of Science, India

\section{Corresponding author:}

Redouane Zitoune, ICA - UMR CNRS 53 I2. Université de Toulouse, I 33 c Avenue de Rangueil, 31077 Toulouse, France.

Email: redouane.zitoune@iut-tlse3.fr 
limit during static and fatigue tests of the machined specimens, respectively. ${ }^{6,7}$ It is important to note that the tool geometry plays a major role in drilling of composites followed by feed rate; many different geometry drill bits made of different tool materials have been tested in the literature. ${ }^{8-11}$ Tool geometries can be summarized into six categories of drill bits: twist drill bit, ${ }^{11-15}$ step drill bit, ${ }^{16}$ brad point drill bit, ${ }^{16-19}$ slot drill bit, ${ }^{19-22}$ straight flute drill bit ${ }^{21,23}$ and trepanning tool (also known as core drill bit). ${ }^{10,24,25}$ If we refer to the literature, ${ }^{18,19}$ the analysis of variance conducted by several authors after the operation of drilling reveals that the main parameter affect the thrust force is the feed speed (by 90\%). However, the spindle speed is responsible only for 5 to $8 \%$ of variation of the thrust force when the machining parameters change.

Most experimental work indicates that damages located at the wall of the hole and at the hole exit (delamination) are considered critical damages lowering the mechanical resistance of the structural parts during fatigue loading. ${ }^{26,27}$ Several authors have confirmed that the damage located at the wall of the hole is strongly influenced by the physics of cutting. ${ }^{28-31}$ In fact, when a conventional drill (e.g. twist drill) is used for drilling with its optimal machining parameters, the critical damage is located in the areas where the relative angle between the cutting lip and the fibre is equal to $-45^{\circ}$ or $90^{\circ}$. However, in the case of drilling with a core drill made of diamond grits and using optimal machining parameters, the state of the wall of the hole is smooth and no critical damage area is observed. ${ }^{10}$

At the exit of the hole, the observed damage takes the form of delamination between the plies. ${ }^{31}$ This defect appears when the thrust forces are too high, which generates a crack propagating at the interface between the two plies. ${ }^{31-35}$ Different authors have shown that this damage is strongly affected by the feed rate and the geometry of the drill, the wear rate of the tool as well as the interface quality between the plies of the composite material. ${ }^{9-15}$ The damage located at the hole exit is the main damage appearing in drilling composite materials. The size of the delamination zone has been shown to be related to the thrust force developed during the drilling process and it is believed that there is a 'critical thrust force' (CTF) below which no damage occurs. ${ }^{33-37}$ In fact, delamination can be greatly reduced or eliminated by reducing feed rates near the exit and using backup plates to support and prevent deformations leading to exit side delamination. ${ }^{38-40}$

In order to predict the CTF responsible for the delamination during drilling with conventional drill (e.g. twist drill), many analytical and numerical models have been developed. ${ }^{33-40}$ Hocheng and
Dharan $^{33}$ proposed the first analytical model for prediction of CTF based on linear elastic fracture mechanics (LEFM) approach for an assumed isotropic material with a circular self-similar crack under a concentric loading. Using the classical bending theory of thin circular plates for a point load and Griffith's energy balance criterion, Hocheng and Dharan were able to derive a compact form of critical thrust force (CFT) for a particular material system. Jain and Yang $^{34}$ modified Hocheng and Dharan's simplistic model by assuming a more realistic elliptical damage zone representative of the inherent orthotropy of a unidirectional laminate (UD) laminate. Jain and Yang ${ }^{34}$ also proposed a unique variable feed rate strategy that enabled delamination-free drilling by reducing the feed rates as the drill bit approached the exit side of the hole. The main results show that it is possible to reduce the thrust force significantly by reducing the chisel edge width. Recently, Saoudi et al. ${ }^{35,36}$ proposed a new model taking into account: (1) the orthotropic behavior of the composite; (2) the coupling between stretching and bending and (3) delineating the contribution of chisel edge and principal cutting edge in a twist drill. The predicted values of the CTF are in good agreement compared to those obtained experimentally. The small difference observed has been attributed mainly to the variability in the thickness of the composite ply due to the process of manufacturing. The presence of this variability has been confirmed using X-ray tomography (in situ observation) conducted before and after punching tests on CFRP specimens. In addition, a three-dimensional (3D) finite element model based on the fracture mechanics allowing CTFs (for a conventional twist drill) responsible for delamination at the hole exit to be predicted is developed using multi-layers elements available in the library of the commercial software SAMCEF. ${ }^{41}$ In the numerical model, the distribution of the loading used corresponds to a contribution of $40 \%$ by the drill chisel edge and of $60 \%$ by the drill lips. The CTF predicted by this model was compared with Hocheng and Dharan predictions. ${ }^{33}$ The results showed that the analytical model underestimates the CTFs. These results are in good agreement with those observed in the literature. ${ }^{36-42}$

In the case of drilling with core drill, few works are available in the literature. ${ }^{10,24,25}$ Cadorin and Zitoune ${ }^{10}$ have noticed that the machining quality of $3 \mathrm{D}$ woven composite obtained with core drill made of diamond grits is better compared to the one obtained with conventional drill with three cutting lips. In addition, the same authors have shown that when drilling is conducted with core drill using machining parameters 


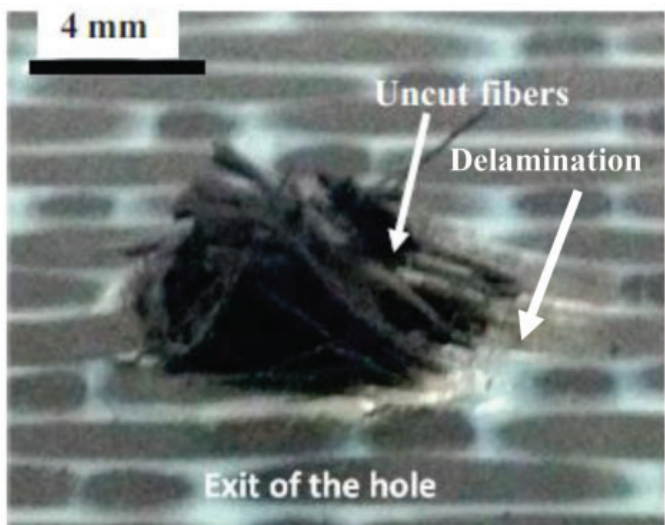

Figure I. Damage generated by worn out core drill after machining with too high feed rate. Feed rate $f=0.08 \mathrm{~mm} / \mathrm{rev}$, spindle speed of $5000 \mathrm{r} / \mathrm{min}$ at the exit of the hole. ${ }^{10}$

that are not optimal, severe damage was observed at the hole exit, such as delamination and uncut fibres (cf. Figure 1). The authors report that real time monitoring of cutting forces during drilling reveals that delamination appears as axial thrust force reaches a critical value. Thus, to overcome these kinds of damage during machining with core drill, it is important to predict this critical value.

The unique analytical models available in the literature to predict CTF during drilling with core drill are proposed by Hocheng and Tsao. ${ }^{24,25}$ In these analytical models, authors assume isotropic properties for the CFRP plate in order to simplify the analysis to predict the CTF during drilling. The comparison between the predicted force and the measured values of the CFT showed that the relative deviation is around $30 \%$; the deviation can be attributed to the over-simplistic isotropic material assumption and the variability in thickness of the composite laminate that results in errors in measurement of CTF experimentally.

The main objective of this study is to propose a new analytical model for predicting CTF for a core drill by assuming a more realistic orthotropic material definition for the composite laminate. Experimental validation of the CTF at different ply thickness under the tool has also been carried out using quasi-static punching tests. Finally, the damage development during drilling has been extensively studied using X-ray tomography observations.

\section{Physical model for the prediction of the critical force when the core drill is used}

For the exit-ply delamination, the transverse displacement $w$ generated by the drill movement is associated with the work done by the thrust force $\mathrm{F}_{\mathrm{Z}}$, which is used to deflect the plate as well as to propagate the inter-laminar crack $^{33}$

The energy balance equation gives

$$
d W-d U=G_{I c} d A
$$

where

$d W$ : is the work done by the external forces.

$d U$ : is the infinitesimal strain energy.

$G_{I c}$ : is the critical strain energy release rate in mode I. $d A$ : is the infinitesimal increase in area of crack.

\section{Delamination model using core drill ${ }^{24}$}

Figure 2 depicts the schematics of a core drill and the induced delamination. In this figure, the tool is characterized by the inner radius $\mathrm{c}^{*}$, outer radius $\mathrm{c}$ and thickness t. $F_{Z}$ is the thrust force related to the lateral uniform distribution load $q, H$ is the workpiece thickness, $h$ is the uncut depth under tool and $a$ is the radius of delamination at which the plate is embedded at the edge. To obtain the CTF, Hocheng and $\mathrm{Tsao}^{24}$ have considered that the material behavior is isotropic. In addition, pure bending of the laminate is assumed in the model. However, the relation between $\left(\mathrm{F}_{1}\right)$ and $\left(\mathrm{F}_{2}\right)$ can be written as $F_{2}=(1-\beta)^{2} F_{1}$.

\section{Proposed model for the core drill}

Figure 3(a) depicts the schematics of the load applied by a core drill.

For the development of the model, the following main assumptions are considered:

- LEFM has been considered.

- Orthotropic behavior and pure bending of the laminate are assumed.

- Drilling-induced delamination has been idealized as a mode I crack propagation phenomenon; the applied thrust force that causes onset of mode I delamination is defined as the CTF.

- The delaminated zone is considered to be a circular plate with orthotropic properties.

- Contact between core drill and composite is assumed to result in uniformly distributed loading.

- A circular pre-crack of nominal diameter is assumed to be present at the start of the analysis. 


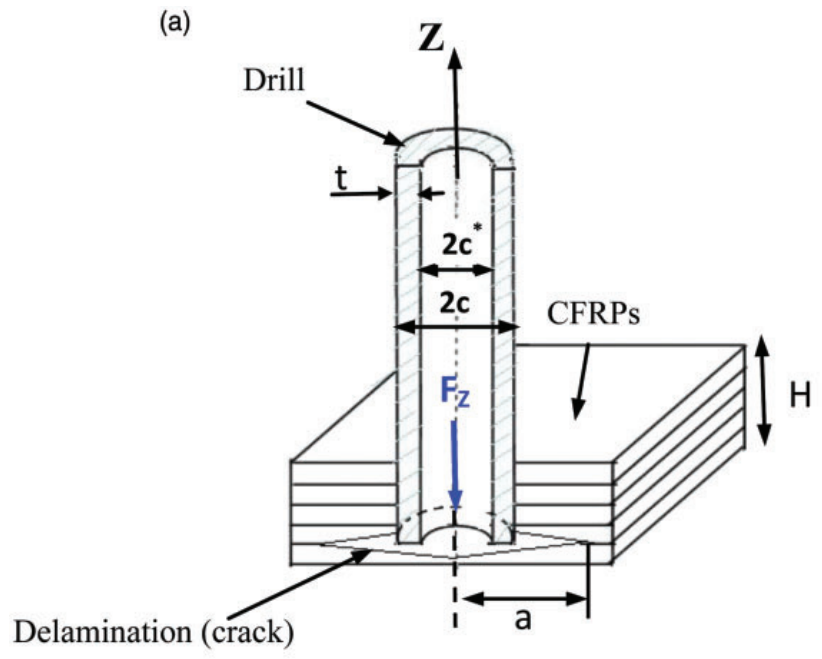

(b)
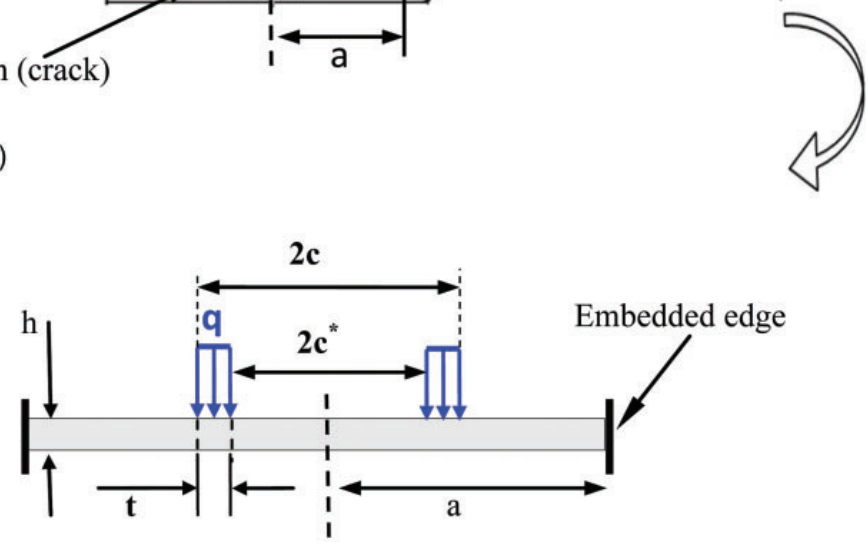

Figure 2. Circular plate model for delamination analysis using a core drill. ${ }^{25}$ (a) Cross view of delamination area. (b) Thrust force model.

(a)

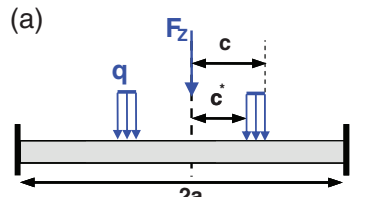

(b)

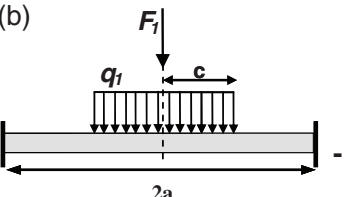

(c)

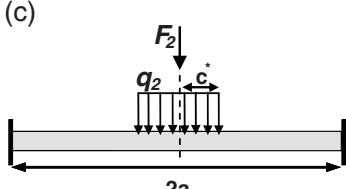

Figure 3. Decomposition of the load applied by the tool (core drill) based on the superposition method.

In order to get the CTF applied by the core drill, the method of superposition is applied. Since the tool-work contact is located in a circular area at the bottom of the drill core, the thrust force due to the action of the core drill is obtained by subtracting the downward force $\left(F_{1}\right)$ from downward force $\left(F_{2}\right)$ as shown in Figure 3(b) and (c).

In this case, the uniformly distributed lateral load $\mathrm{q}_{1}$ acting on the downward area and the uniformly distributed lateral load $\mathrm{q}_{2}$ must be equal. However, the relation between $\left(F_{1}\right)$ and $\left(F_{2}\right)$ can be written as follows

$$
F_{2}=(1-\beta)^{2} F_{1}
$$

The thrust force can be written then as follows

$$
F_{Z}=F_{1}-F_{2}=\beta(2-\beta) F_{1}
$$

Delamination analysis: model (b). For this model, the energy balance equation (1) can be expressed as follows

$$
d W_{1}-d U_{1}=G_{I}^{1} d A
$$

For an orthotropic circular plate of radius $a$, clamped at the edges and subjected to uniformly distributed load over a central circular area of radius $c$, the following closed form solutions for transverse 
deflections of the plate have been detailed by assuming an axisymmetric analysis ${ }^{43}$

(i) $0 \leq r \leq c$ inner portion

$$
\begin{aligned}
w= & \frac{F_{1}}{64 \pi D}\left[\left(4 a^{2}-3 c^{2}+4 c^{2} \log \frac{c}{a}\right)\right. \\
& \left.-2 r^{2}\left(\frac{c^{2}}{a^{2}}-4 \log \frac{c}{a}\right)+\frac{r^{4}}{c^{2}}\right]
\end{aligned}
$$

(ii) $c \leq r \leq a$ outer portion

$$
\begin{aligned}
w= & \frac{F_{1}}{64 \pi D}\left[4 a^{2}+2 c^{2}-2 r^{2}\left(2+\frac{c^{2}}{a^{2}}\right)\right. \\
& \left.+4 c^{2} \log \frac{r}{a}+8 r^{2} \log \frac{r}{a}\right]
\end{aligned}
$$

where

$$
D=\frac{1}{8}\left(3 D_{11}+2 D_{12}+4 D_{66}+3 D_{22}\right)
$$

$D$ : is the bending rigidity of the plate.

$D_{i j}(i, j=1,2$ and 6$)$ : are the coefficients of the matrix of bending stiffness.

- Strain energy derivation $d U_{1}$ :

The expression for strain energy can be written as follows

$$
\begin{aligned}
2 U_{1}= & \iint\left[D_{11}\left(\frac{\partial^{2} w}{\partial x^{2}}\right)^{2}+D_{22}\left(\frac{\partial^{2} w}{\partial y^{2}}\right)^{2}\right. \\
& \left.+4 D_{66}\left(\frac{\partial^{2} w}{\partial x \partial y}\right)^{2}+2 D_{12}\left(\frac{\partial^{2} w}{\partial x^{2}}\right)\left(\frac{\partial^{2} w}{\partial y^{2}}\right)\right] \mathrm{d} x \mathrm{~d} y
\end{aligned}
$$

Equation (8) can be written as

$$
2 U_{1}=U_{11}+U_{22}+U_{66}+U_{12}
$$

where

$$
\left.\begin{array}{rl}
U_{11} & =\iint D_{11}\left(\frac{\partial^{2} w}{\partial x^{2}}\right)^{2} \mathrm{~d} x \mathrm{~d} y \\
U_{22} & =\iint D_{22}\left(\frac{\partial^{2} w}{\partial y^{2}}\right)^{2} \mathrm{~d} x \mathrm{~d} y \\
U_{66} & =\iint 4 D_{66}\left(\frac{\partial^{2} w}{\partial x \partial y}\right)^{2} \mathrm{~d} x \mathrm{~d} y \\
U_{12} & =\iint 2 D_{12}\left(\frac{\partial^{2} w}{\partial x^{2}}\right)\left(\frac{\partial^{2} w}{\partial y^{2}}\right) \mathrm{d} x \mathrm{~d} y
\end{array}\right\}
$$

In polar coordinates, equation (10) can be written as

$$
\begin{aligned}
& U_{11}=\int_{0}^{2 \pi} \int_{0}^{a} D_{11}\left(\frac{\partial^{2} w}{\partial r^{2}} \cos ^{2} \theta+\frac{\partial w}{\partial r} \frac{\sin ^{2} \theta}{r}\right)^{2} r \mathrm{~d} r \mathrm{~d} \theta \\
& U_{22}=\int_{0}^{2 \pi} \int_{0}^{a} D_{22}\left(\frac{\partial^{2} w}{\partial r^{2}} \sin ^{2} \theta+\frac{\partial w}{\partial r} \frac{\cos ^{2} \theta}{r}\right)^{2} r \mathrm{~d} r \mathrm{~d} \theta \\
& U_{12}=\int_{0}^{2 \pi} \int_{0}^{a} 2 D_{12}\left(\frac{\partial^{2} w}{\partial r^{2}} \cos ^{2} \theta+\frac{\partial w}{\partial r} \frac{\sin ^{2} \theta}{r}\right) \\
& \times\left(\frac{\partial^{2} w}{\partial r^{2}} \sin ^{2} \theta+\frac{\partial w}{\partial r} \frac{\cos ^{2} \theta}{r}\right) r \mathrm{~d} r \mathrm{~d} \theta \\
& U_{66}=\int_{0}^{2 \pi} \int_{0}^{a} 4 D_{66}\left(\begin{array}{c}
\frac{\partial^{2} w}{\partial r^{2}} \sin \theta \cos \theta \\
-\frac{\partial w}{\partial r} \frac{\sin \theta \cos \theta}{r}
\end{array}\right)^{2} r \mathrm{~d} r \mathrm{~d} \theta
\end{aligned}
$$

where

$(\mathrm{r}, \theta)$ : are the polar coordinates.

By introducing equations (5) and (6) into (11), we obtain

$$
\begin{aligned}
& U_{11}=\left(\frac{F_{1}}{32 D}\right)^{2} \frac{D_{11}}{\pi}\left[48 c^{2} \log \left(\frac{c}{a}\right)-\frac{6 c^{4}}{a^{2}}-16 c^{2}+24 a^{2}\right] \\
& U_{22}=\left(\frac{F_{1}}{32 D}\right)^{2} \frac{D_{22}}{\pi}\left[48 c^{2} \log \left(\frac{c}{a}\right)-\frac{6 c^{4}}{a^{2}}-16 c^{2}+24 a^{2}\right] \\
& U_{12}=\left(\frac{F_{1}}{32 D}\right)^{2} \frac{D_{12}}{\pi}\left[32 c^{2} \log \left(\frac{c}{a}\right)-\frac{4 c^{4}}{a^{2}}-\frac{32}{3} c^{2}+16 a^{2}\right] \\
& U_{66}=\left(\frac{F_{1}}{32 D}\right)^{2} \frac{D_{66}}{\pi}\left[64 c^{2} \log \left(\frac{c}{a}\right)-\frac{8 c^{4}}{a^{2}}-\frac{64}{3} c^{2}+32 a^{2}\right]
\end{aligned}
$$

\section{Strain energy derivation}

$2 d U_{1}=\frac{d U_{1}}{d a} d a=\left(\frac{d U_{11}}{d a}+\frac{d U_{22}}{d a}+\frac{d U_{12}}{d a}+\frac{d U_{66}}{d a}\right) d a$

Finally, by replacing equation (12) into equation (13), we obtain

$$
d U_{1}=\frac{F_{1}^{2} a}{32 \pi D} \frac{D^{\prime}}{8 D}\left(3 s^{4}-12 s^{2}+12\right) d a
$$

where

$s=\frac{c}{a}:$ drill diameter to delamination diameter ratio

$$
D^{\prime}=\frac{D_{11}+D_{22}}{2}+\frac{D_{12}+2 D_{66}}{3}: \text { stiffness coefficient }
$$


- Work of external forces derivation $d W_{1}$ :

The expression of the work of the external forces is given by

$$
W_{1}=\int_{0}^{2 \pi} \int_{0}^{c} q_{1} w r \mathrm{~d} r \mathrm{~d} \theta
$$

By substituting equations (5) and (6) into equation (14), we obtain

$$
\begin{gathered}
W_{1}=\frac{F_{1}^{2}}{32 \pi D}\left[4 c^{2} \log \left(\frac{c}{a}\right)-\frac{c^{4}}{2 a^{2}}-\frac{4}{3} c^{2}+2 a^{2}\right] \\
d W_{1}=\frac{d W_{1}}{d a} d a
\end{gathered}
$$

Introducing equations (5), (15) and (18) into equation (19), we obtain

$$
d W_{1}=\frac{F_{1}^{2} a}{32 \pi D}\left(s^{4}-4 s^{2}+4\right) d a
$$

Delamination analysis: model (c). This model is similar to the latter model (b). Thus, the following equations can be given as follows

$$
d W_{2}-\mathrm{d} U_{2}=G_{I}^{2} \mathrm{~d} A
$$

- Strain energy derivation $d U_{2}$

$$
d U_{2}=\frac{d U_{2}}{d a} d a=\frac{F_{2}^{2} a}{32 \pi D} \frac{D^{\prime}}{8 D}\left(3 s^{*^{4}}-12 s^{*^{2}}+12\right) d a
$$

- Work of external forces derivation $d W_{2}$

$$
d W_{2}=\frac{F_{2}^{2} a}{32 \pi D}\left(s^{*^{4}}-4 s^{*^{2}}+4\right)
$$

where

$$
s^{*}=\frac{c^{*}}{a}
$$

Delamination analysis for core drill: model (a). For this model, the energy balance equation (1) can be expressed as follows

$$
d\left(W_{1}-W_{2}\right)-d\left(U_{1}-U_{2}\right)=G_{I} \mathrm{~d} A
$$

where

$$
d A=2 \pi a d a
$$

By introducing equations (2), (14), (20), (22), (23) and (26) into equation (25), we obtain

$$
F_{1}=\pi \sqrt{\frac{64 G_{I} D}{k_{1} s^{4}+k_{2} s^{2}+k_{3}}}
$$

where

$$
\left.\begin{array}{l}
k_{1}=\left(1-\frac{3 D^{\prime}}{8 D}\right)\left(1-(1-\beta)^{8}\right) \\
k_{2}=\left(\frac{3 D^{\prime}}{2 D}-4\right)\left(1-(1-\beta)^{6}\right) \\
k_{3}=\left(4-\frac{3 D^{\prime}}{2 D}\right)\left(1-(1-\beta)^{4}\right)
\end{array}\right\}
$$

By introducing equation (27) into equation (3), thrust force $F_{Z}$ can be calculated

$$
F_{Z}=\pi \beta(2-\beta) \sqrt{\frac{64 G_{I} D}{k_{1} s^{4}+k_{2} s^{2}+k_{3}}}
$$

Finally, for $G_{I}=G_{I c}$, The CTF at the onset of crack propagation becomes

$$
F_{Z C}=\pi \beta(2-\beta) \sqrt{\frac{64 G_{I c} D}{k_{1} s^{4}+k_{2} s^{2}+k_{3}}}
$$

\section{Experimental procedure}

\section{Specimen preparation}

A carbon/epoxy material usually used in the civil aircraft (air bus) was selected to conduct experimental validation of the proposed core drill CTF model. This material, referenced under T700/M21-GC, was supplied by Hexcel Composite Company. According to Hexcel Composite Company, the recommended curing process for this composite was followed: temperature at $180^{\circ} \mathrm{C}$ for $120 \mathrm{~min}$ during which the pressure was maintained at seven bars in an autoclave while the vacuum pressure was set to $0.7 \mathrm{bar}$. In this condition of manufacturing, the theoretical ply thickness of this prepreg material is around $0.26 \mathrm{~mm}$, fibre content $\mathrm{V}_{\mathrm{f}}=59 \%$, a longitudinal Young's modulus $\mathrm{E}_{1 \mathrm{ll}}=142 \mathrm{GPa}$, a transverse Young's modulus $\mathrm{E}_{\mathrm{tt}}=8.4 \mathrm{GPa}$, a shear modulus $\mathrm{G}_{\mathrm{lt}}=3.8 \mathrm{GPa}$ and a glass transition temperature $\mathrm{T}_{\mathrm{g}}=187^{\circ} \mathrm{C}$. The lay-up sequence of the tested plates was quasi-isotropic with a stacking sequence of $[0 /-45 / 90 / 45]_{2 \mathrm{~S}}$. Table 1 summarizes the mechanical properties of the chosen T700/M21GC composite material. 


\section{Punching tests}

For the validation of the proposed CTF model predictions, CFRP specimens with blind holes have been subjected to punching tests as per the procedure outlined

Table I. Mechanical properties of HexPlyT700-M2I-GC. ${ }^{44}$

Mechanical properties of the materials (T700-M2I)

Young's modulus in the $\mathrm{L}$ direction (GPa)

Young's modulus in the $\mathrm{T}$ direction $(\mathrm{GPa})$

Shear modulus (GPa)

Poisson's ratio

Ply thickness $(\mathrm{mm})$

Fibre content (\%)

Critical strain energy release rate in mode $\mathrm{I}\left(\mathrm{J} / \mathrm{m}^{2}\right)$ by Saoudi et al. ${ }^{36}$ and Zitoune and Collombet. ${ }^{41}$ Foremost, the total thickness of the laminate and the total number of the plies were measured in order to determine the average ply thickness. Consequently, blind holes are obtained using a computer numerical control machine based by controlling the machined depth to obtain one ply, two plies, three plies etc. under the tool (cf. Figure 4(a)). In the present work, drilling was conducted using a core drill with a nominal diameter of $8.5 \mathrm{~mm}$. This core drill is manufactured by Ashai Company and made of electro deposited diamond grits (cf. Figure 5). Following the recommendation of Ashai, the core drill used in the current study had an average grit size of $151 \mu \mathrm{m}$. In addition, the synthetic diamond grits are embedded in a nickel matrix with $50 \%$ of crimping rate. The machining parameters used for drilling are $0.08 \mathrm{~mm} / \mathrm{rev}$ feed rate and $8000 \mathrm{r} / \mathrm{min}$ spindle speed. These parameters are based on the previous work and yield a machining quality

(b)

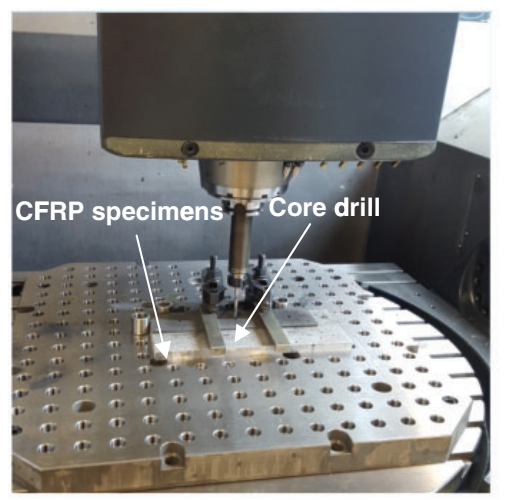

Figure 4. Specimen preparation for the punching tests. (a) Drilling of the blind holes with CNC machine using core drill. (b) Cutting of the specimens with blind holes using abrasive water jet process.

CNC: computer numerical control.

(a)

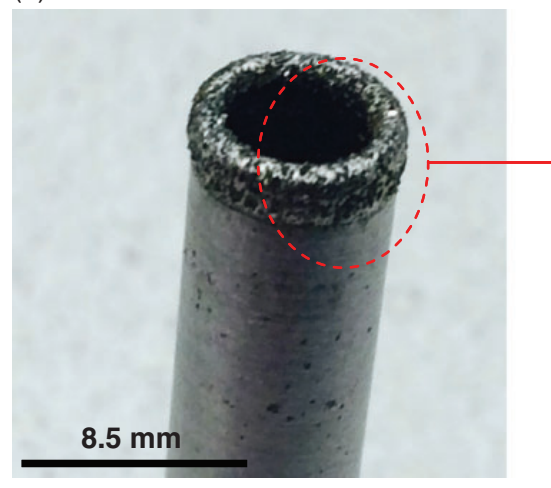

(b)

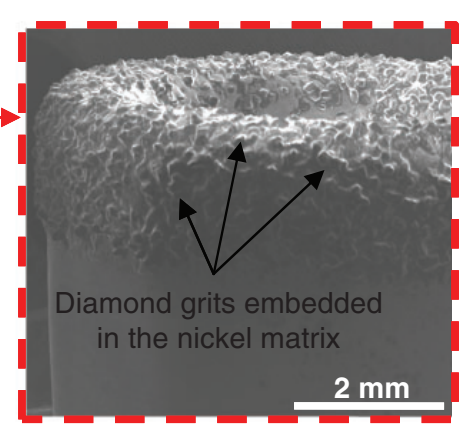

Figure 5. Core drill used the preparation of blind holes and the punching tests. (a) Global view carried out by optical microscopy and (b) SEM image of the local view of the active zone.

SEM: scanning electron microscope. 
Table 2. Characteristic geometric of the core drill made of diamond grit.

\begin{tabular}{ll}
\hline Tool (core drill) & \\
\hline External diameter $(2 \mathrm{c})$ & $8.5 \mathrm{~mm}$ \\
Internal diameter $\left(2 \mathrm{c}^{*}\right)$ & $4.3 \mathrm{~mm}$ \\
Grit material & Diamond D3H \\
Grit agent & $15 \mathrm{Im}$ \\
Bonding agent & Nickel \\
Crimping rate & $50 \%$ \\
Tool body material & High speed steel \\
Feed rate & $0.08 \mathrm{~mm} / \mathrm{rev}$ \\
Spindle speed & $8000 \mathrm{r} / \mathrm{min}$ \\
\hline
\end{tabular}

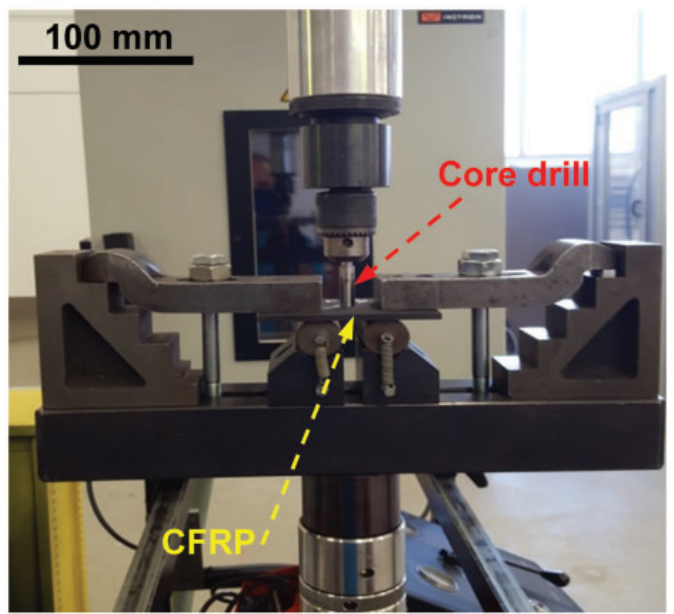

Figure 6. Drilling fixture of punching tests on quasi-isotropic specimens conducted on universal testing machine.

without delamination and fibres pull-out on the wall of the holes. ${ }^{10}$

For the punching tests, specimens with blind holes are cut from the same mother plate in order to reduce the variability in thickness and mechanical properties due to the manufacturing process. ${ }^{44}$ These specimens with dimensions of $100 \times 60 \mathrm{~mm}$ were cut using water jet process (cf. Figure 4(b)).

The geometry of the core drill and the machining parameters used for machining and for the punching tests are summarized in Table 2.

The punching tests were conducted on INSTRON traction machine with max loading of $10 \mathrm{kN}$. During the punching tests, the selected specimens were positioned on two supports and clamped (Figure 6). The punching load was applied at rate of $1 \mathrm{~mm} / \mathrm{min}$ with the same drill previously used for machining the blind holes. For each configuration of the number of plies under the tool, the test was repeated three times.

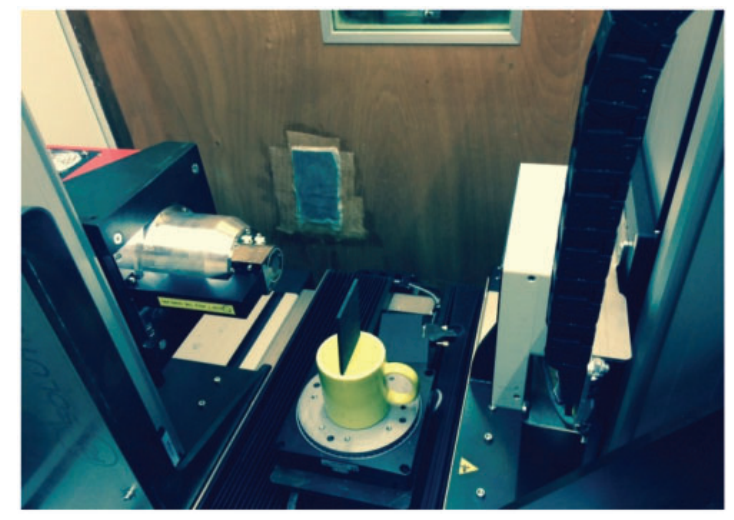

Figure 7. Tomography view for analyzing specimens before punching tests.

Punching load versus drill displacement data was recorded by the INSTRON data acquisition system.

\section{X-ray tomography and postmortem observation}

If we refer to previous work, the control of the thickness of the uncut laminate under the drill remains a challenge due to the inherent variability induced by the manufacturing process of the CFRP laminates. $^{12,21,44}$ For the quantification of the variability such as the in situ thickness of the uncut laminates of the blind holes, X-ray tomography is conducted on all the specimens prior the punch tests. This method of characterization helps to explain the influence of the variation of the in situ thickness of the CTF after the punching tests. Measurements with X-ray micro-computed tomography were carried out using MicroTomography Easy Tom 130 machine. Each specimen was exposed to radiation and rotated through $360^{\circ}$ to capture the images for $3 \mathrm{D}$ construction (Figure 7). The $\mathrm{X}$-ray voltage and current were set as $130 \mathrm{kV}$ and 300 $\mathrm{mA}$, respectively. X-rays were diverged conically from the source and received by the receiver after encountering the specimen. The specimens of $60 \mathrm{~mm}$ width were exposed at a distance of $80 \mathrm{~mm}$ to the source. The source has a spot size of $3 \mu \mathrm{m}$. Each sample was scanned for $70 \mathrm{~min}$ with $0.01 \mathrm{~s}$ per projection. In this condition of measurement, the maximum possible resolution is around $40 \mu \mathrm{m}$.

\section{Results and discussion}

Figure 8 represents the load versus displacement plots obtained during punching tests for different number of plies under the tool (one ply, two plies and three plies). It can be observed that the applied force by the core drill increases linearly till a critical value. This critical value that represents the CTF is strongly influenced by 


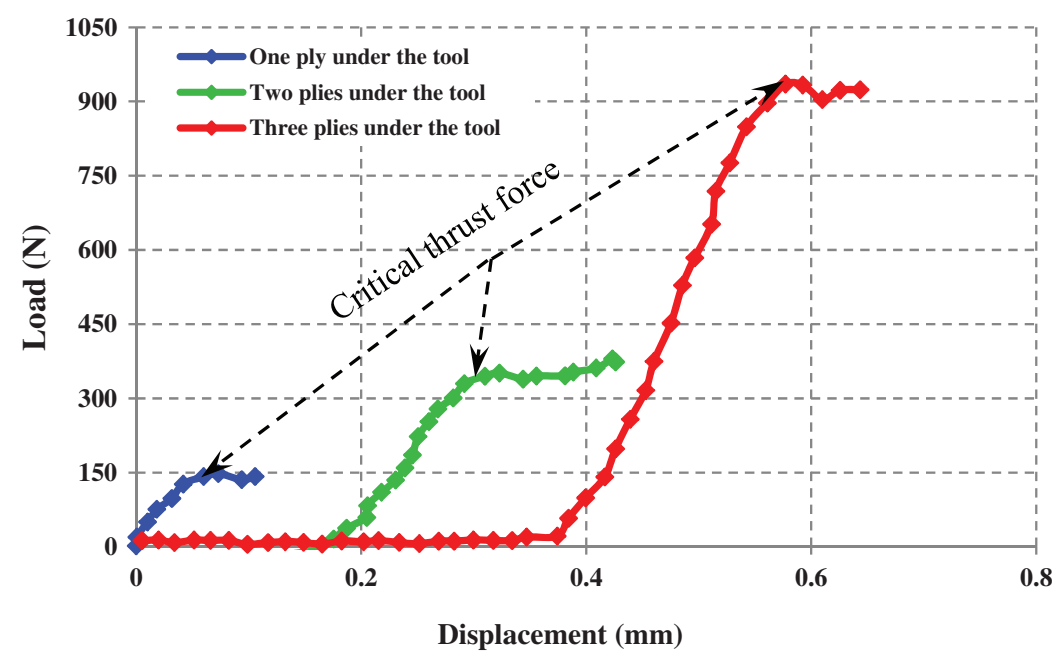

Figure 8. Punching axial force with different number of plies under the tool.

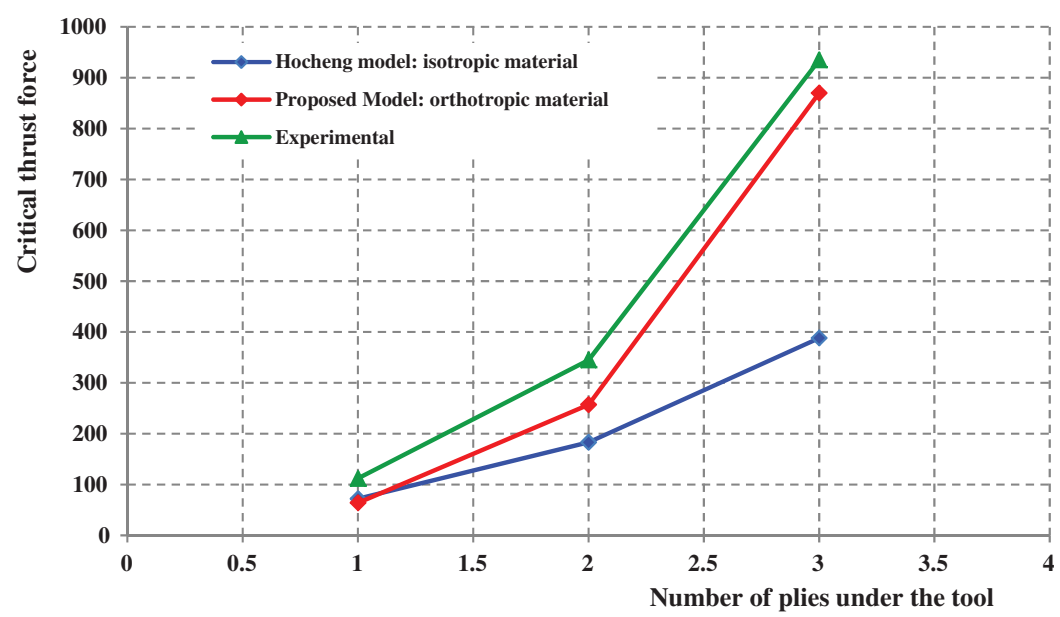

Figure 9. Evolution of the critical thrust force for different plies under the tool for $\beta=0.24$ and $\mathrm{s}=0.8$ (with: $\mathrm{c}=4.25 \mathrm{~mm}$, $t=1.02 \mathrm{~mm}$ and $c^{*}=3.23 \mathrm{~mm}$ ): Comparison between the experimental values, Hocheng model ${ }^{24}$ and the proposed model.

the number of plies under the drill. Thereafter, a sudden reduction of force is observed, which can be explained by the initiation and the propagation of crack. The evolution of the force as a function of the displacement is similar to those observed in the literature for punching tests conducted on twist drills; however, the maximum level of the recorded forces is different. ${ }^{36,41}$ This can be explained by the local contact condition tool/CFRP being different resulting in different load distributions for a core drill as compared to twist drill.

Figure 9 depicts a comparison between the CTF obtained by the proposed model (assuming an orthotropic material, dedicated by the equation (30)), the model proposed in the literature by Hocheng and $\mathrm{Tsao}^{24}$ (assuming an isotropic material) and the experimental values of the punching tests. From this figure, it can be confirmed that with increasing the number of plies under the tool (from one ply till three plies), the measured CTF increases by $885 \%$.

As the number of plies under the tool increases, the uncut thickness and bending stiffness increase proportionately resulting in higher CTF predictions that match with experimental punching test data. The Hocheng model from literature assuming an isotropic material underestimates the critical values of the CTF. The deviation from experimental data becomes more pronounced for increasing number of uncut plies under the drill. As a matter of fact, the relative deviation between the measured values and Hocheng mode ${ }^{24}$ is around 23 and $56 \%$ for one ply and three plies under the tool, respectively. In contrast, for the proposed model, the average deviation between the measured values and the predicted CTF is around 
14 and $23 \%$ when three plies and one ply under the tool is considered, respectively. In fact, the good agreement of the CTF observed between the proposed model and the experimental values can be explained by the fact that the proposed model is more representative of the material nature (orthotropic phenomenon).

However, the gap observed between the experimental values and the predicted values by the proposed model of the CTF can be explained mainly by the random variation of the ply thickness of the laminates. This explanation is confirmed by the X-ray tomography of the CFRP specimens observed for different uncut plies with blind holes obtained before the punching tests (cf. Figure 10). From these observations, it is clear that the thickness of the uncut part located under the drill for one ply under the tool is around $0.29 \mathrm{~mm}$ (Figure 10(b)), which does not correspond to the theoretical value recommended by the manufacturer of the prepreg (which is equal to $0.26 \mathrm{~mm}$ ). Also, in the case of two plies under the tool, the measured uncut thickness is around $0.42 \mathrm{~mm}$ which represents a relative deviation of $19 \%$ compared to the theoretical value $(0.52 \mathrm{~mm})$. In addition, to this variability in the ply thickness due to the process of manufacturing of the composite structures, ${ }^{35,36,44}$ the X-ray tomography images reveal that, in the vicinity of the applied loading, the geometry of the blind holes (or the uncut part) does not represent totally a plane surface as is considered in the analytical model. In fact, an overthickness around of $0.43 \mathrm{~mm}$ is observed for all the specimens tested due to the core drill geometry. Otherwise, the postmortem observation conducted by X-ray tomography after punching test of some specimens reveals the clear presence of an inter-laminar crack for the
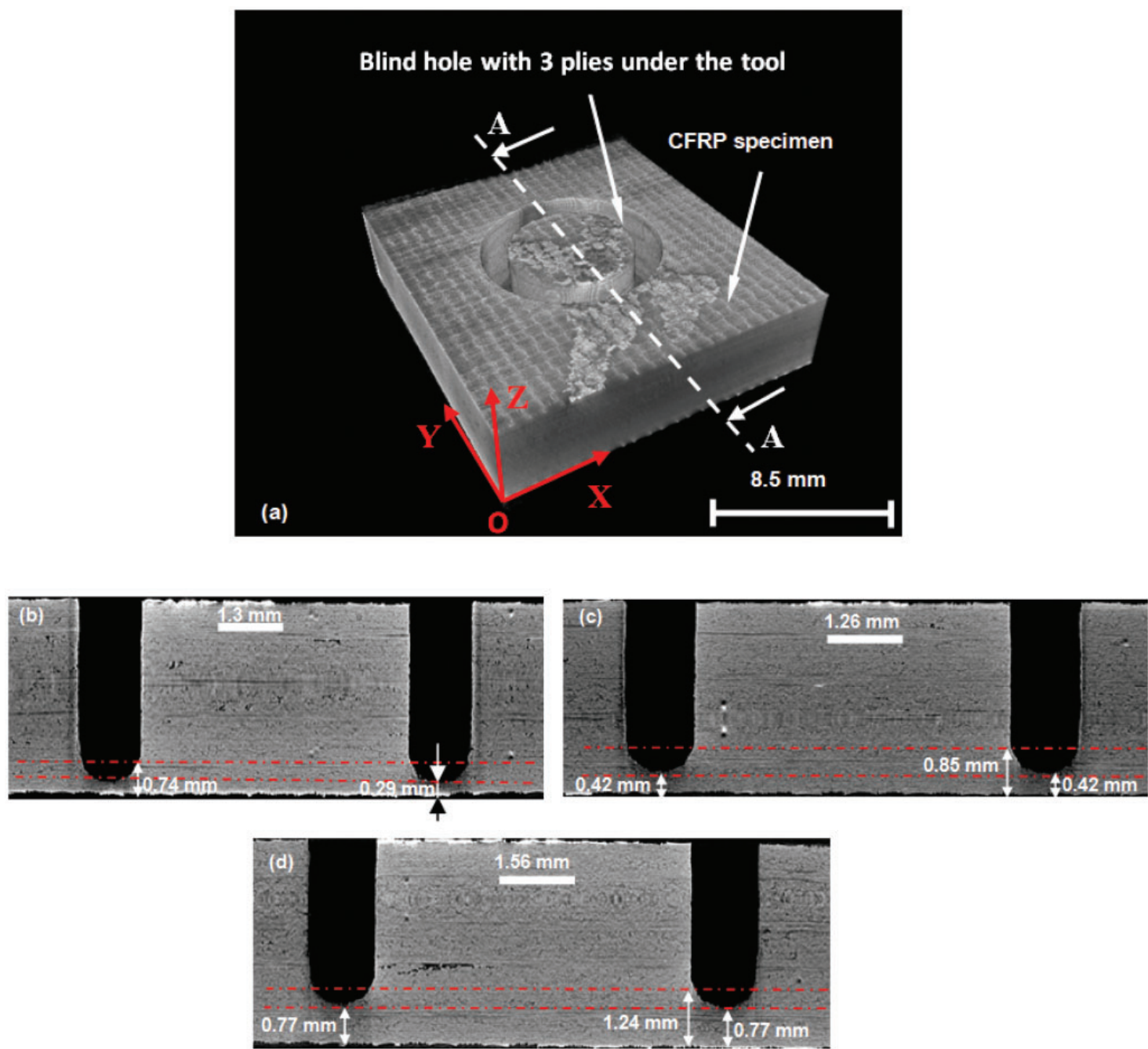

Figure 10. Postmortem observation of the blind holes before the punching tests. (a) 3D image of the CFRP specimen with three plies under the tool with schematic view of the cross section (A-A). (b), (c) and (d) Cross section (A-A) of the specimens with one ply, two plies and three plies under the tool, respectively.

CFRP: carbon fibre-reinforced plastics; 3D: three-dimensional. 
specimens with one and two plies under the tool. These inter-laminar cracks are characterized by a size of $0.95 \mathrm{~mm}$ to greater than $2 \mathrm{~mm}$ for one ply under the tool and two plies under the tool, respectively (cf. Figure 11(a) and (b)). It is important to mention that the size of the inter-laminar crack used in the analytical model (which is equal to $1 \mathrm{~mm}$ ) is representative of the crack identified experimentally from the X-ray tomography images. However, for the specimens with three plies under the tool, the postmortem observations reveal the presence of inter-laminar and intra-laminar cracks with a size of 1.33 and $0.4 \mathrm{~mm}$, respectively (cf. Figure 11(c)). From these observations, it can be concluded that the phenomena of the variability described above have an important influence on the initiation as well as on the propagation of the crack.

Additionally, deviation observed between the predicted CTF and the measured values can also be attributed to: (1) neglecting the effect of bending and stretching coupling that is commonly observed in CFRP and (2) the residual strains due to the curing phase that induces some local deformation in the geometry of the blind hole as well as the geometry of the core drill which leaves à footprint different from the one supposed in the analytical model (plane shape).

The uniqueness of the proposed model (equation (30)) for the prediction of the CTF is the fact that it takes into account the tool geometry (internal and external diameters) compared to the other models available in the literature. ${ }^{17,18,20,33-36,38-40}$ In this context, Figure 12 represents the evolution of CTF with respect to ' $s$ ' (delamination diameter ratio) for different ratios of ' $\beta$ ' (thickness of the core drill) when one ply under the tool is considered. It can be observed from Figure 12 that for a given value of $\beta=0.2$, the critical thrust remains stable (around $18 \mathrm{~N}$ ) when the
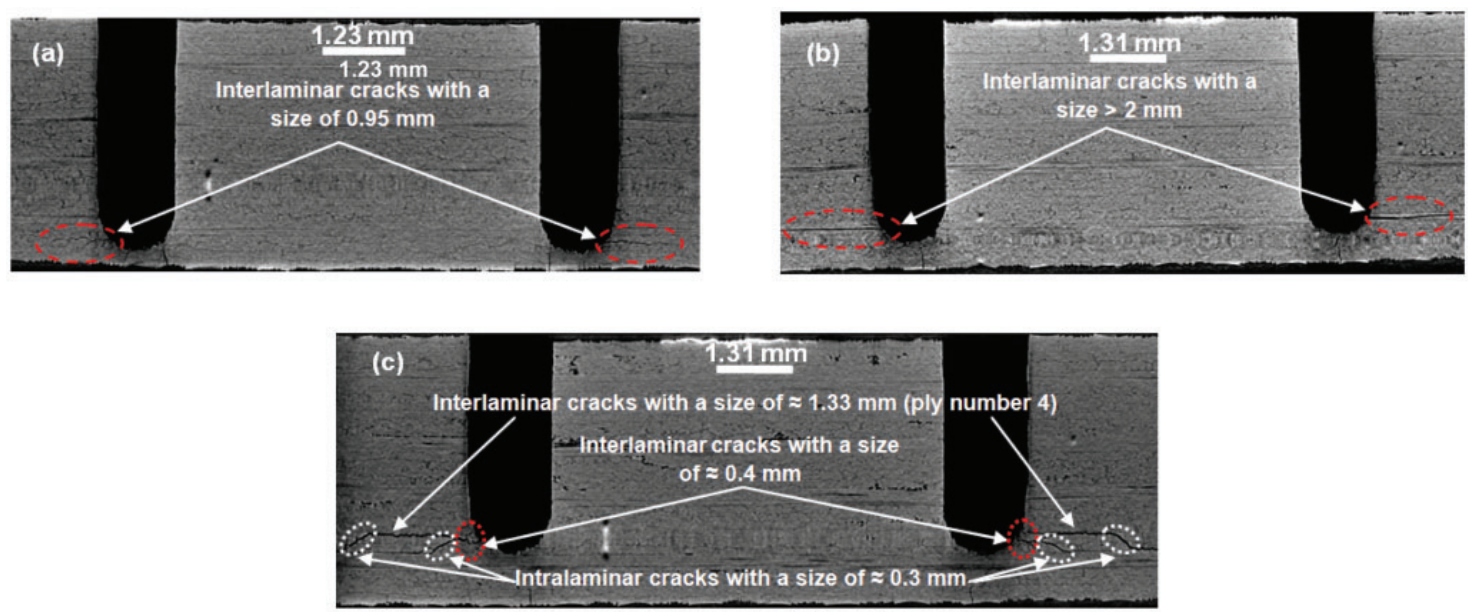

Figure II. Postmortem observation of the specimens after punching tests. With (a) cross section of specimen with one ply under the tool, (b) cross section of specimen with two plies under the tool and (c) cross section of specimen with three plies under the tool.

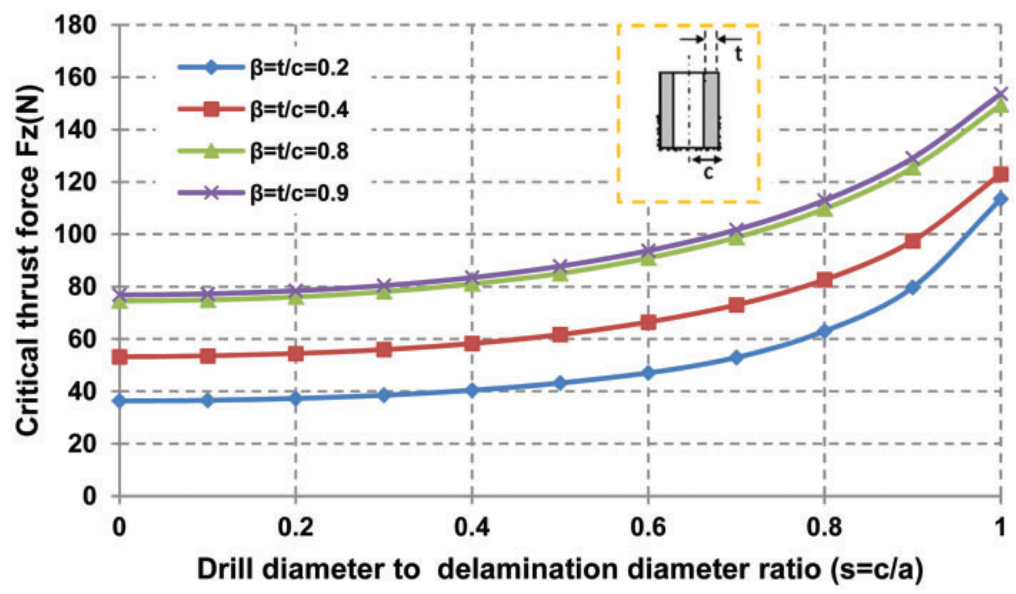

Figure 12. Critical thrust force ratio for one ply under the core drill. 


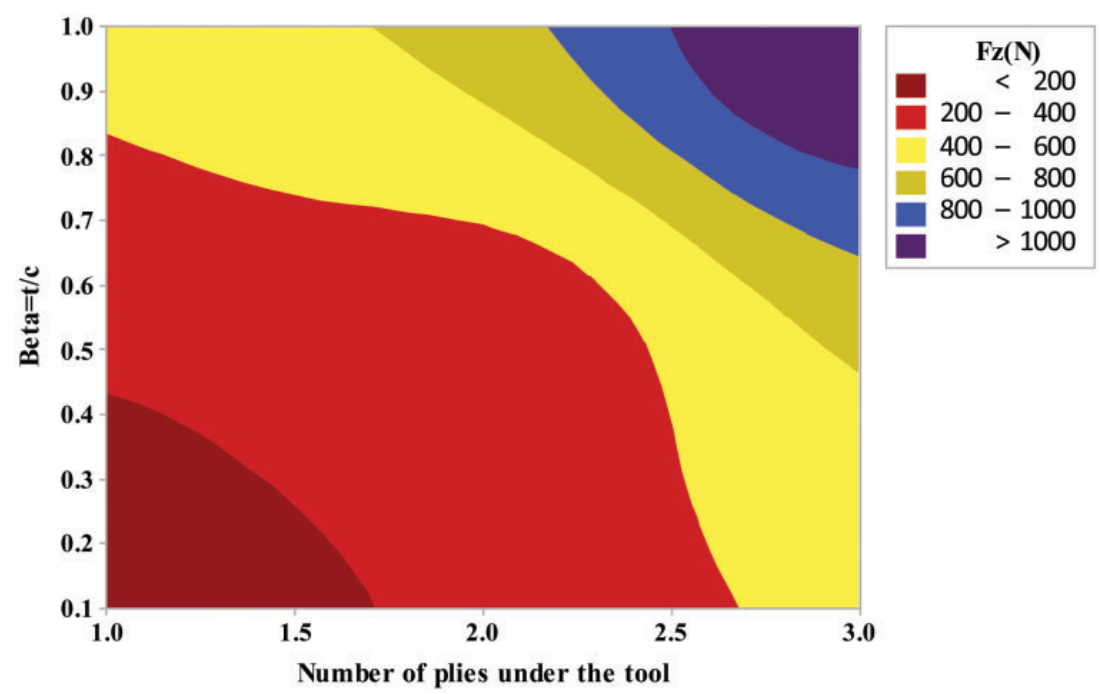

Figure 13. Cartography of the critical thrust force $\left(F_{z}\right)$ in function of tool geometry and the number of plies under the tool for delamination ratio $(s=c / a=0.8)$.

delamination ratio varies from 0 to 0.3 . However, when the delamination ratio increases from 0.3 till 1 , the CTF predicted by the model increases by $188 \%$ (from 18 to $52 \mathrm{~N}$ when $\beta=0.2$ ).

The cartography presented in Figure 13 shows the distribution of the CTF obtained from the equation (30) as a function of $\beta$ and the number of the plies under the tool. From this cartography, the critical value of the thrust force can be identified for different ratios of the parameter $\beta$ of the core drill. For example, in the case of the parameters of the core drill presented in Table 2 of the section $3.2(\mathrm{t}=2.1 \mathrm{~mm}, 2 \mathrm{c}=8.5 \mathrm{~mm}$ and $\beta=0.24)$, the critical values of the thrust force as a function of the number of plies under the core drill correspond the dashed line on the Figure 13. In this case, a good agreement of the predicted value and the measured value is observed. For other core drill geometry, CTF predictions can be used as guideline to prevent exit side drilling-induced delamination.

\section{Conclusions}

From the present study, a more realistic analytical model for CTF prediction using a core drill has been presented. The originality of this model lies in the use of orthotropic properties for the composite ply as applicable for drilling of multi-directional composite laminates. The proposed model CTF predictions were compared to those from the literature (with isotropic material property assumptions). ${ }^{24,25}$ The efficacy of the proposed model is further established by comparison of the predicted CTF with push-out experiments combined by the postmortem observations making use of $\mathrm{X}$-ray tomography technique conducted before and after the punching tests. From the results of the proposed model and the experimental tests, the following conclusions can be drawn:

- From the comparison between the model available in the literature ${ }^{24,25}$ which allows to predict the CTF responsible for delamination at the hole exit during drilling of CFRP using core drill, the proposed model and the measured value of CTF, it is confirmed that the model proposed by Hocheng and $\mathrm{TsaO}^{24}$ underestimated the CTF. The predicted CTF value obtained by the proposed model is in good agreement with the experimental values of the CTF. This explains the importance of choosing appropriate material properties and associated mechanical behavior composite laminates that affect stiffness, thereby contributing to CTF predictions.

- By conducting X-ray tomography experiments prior to the punch tests, the uncut laminate thickness was considered as the main factor responsible of the deviation observed between the predicted and measured CTF. Indeed, the difference in the thrust force predicted and measured during punching tests can be attributed to the local variation in ply thickness of the laminate due to the manufacturing process of the laminate. In addition, the postmortem observation of the specimens after punching tests reveals the clear presence of an opening crack phenomenon by mode I and some intra-laminar cracks that the model does not take into account.

\section{Declaration of Conflicting Interests}

The author(s) declared no potential conflicts of interest with respect to the research, authorship, and/or publication of this article. 


\section{Funding}

The author(s) received no financial support for the research, authorship, and/or publication of this article.

\section{References}

1. Research LM. Growth opportunities in global carbon fiber market, 2015.

2. Gunston B. Airbus: The complete story. 2nd ed. Somerset: Haynes Publishing, 2009.

3. Arul S, Vijayaraghavan L, Malhotra SK, et al. The effect of vibratory drilling on hole quality in polymeric composites. Int J Mach Tool Manufact 2006; 46: 252-259.

4. Krishnamoorthy A, RajendraBoopathy $\mathrm{S}$ and Palanikumar K. Delamination prediction in drilling of CFRP composites using artificial neural network. J Eng Sci Tech 2011; 6: 191-203.

5. Prakash S, Palanikumar K and Krishnamoorthy A. Thrust force evaluation in drilling medium density fibre (MDF) panels using design of experiments. Int J Manuf Tech Manag 2012; 25: 95-112.

6. Zitoune R, Vijayan K, Collombet F, et al. Experimental and numerical analysis on drilling of carbon fibre reinforced plastic and aluminium stacks. Compos Struct 2016; 146: $148-158$

7. Zitoune R, Krishnaraj V, Almabouacif S, et al. Influence of machining parameters and new nano-coated tool on drilling performance of $\mathrm{CFRP} /$ aluminium sandwich. Compos B Eng 2012; 43: 1480-1488.

8. Tsao CC, Kuo KL and Hsu IC. Evaluation of a novel approach to a delamination factor after drilling composite laminates using a core-saw drill. Int J Adv Manuf Tech 2012; 56: 617-622.

9. Karimi NZ, et al. Critical thrust force and feed prediction models in drilling of composite laminates. Compos Struct 2016; 148: 19-26.

10. Cadorin $\mathrm{N}$ and Zitoune $\mathrm{R}$. Wear signature on hole defects as a function of cutting tool material for drilling 3D interlock composite. Wear 2015; 332-333: 742-751.

11. Cadorin N, Zitoune R, Seitier P, et al. Analysis of damage mechanism and tool wear while drilling of $3 \mathrm{D}$ woven composite materials using internal and external cutting fluid. J Compos Mater 2015; 49: 2687-2703.

12. Grilo TJ, et al. Experimental delamination analyses of CFRPs using different drill geometries. Compos B 2013; 45: $1344-1350$.

13. Konig W, Wulf C, Gras $\mathrm{P}$, et al. Machining of fibre reinforced plastics. CIRP Ann-Manuf Tech 1985; 34: 537-548.

14. Mohan NS, Ramachandra A and Kulkarni SM Influence of process parameters on cutting force and torque during drilling of glass-fiber polyester reinforced composites. Compos Struct 2005; 71: 407-413.

15. Shyha IS, Aspinwall DK, Soo SL, et al. Drill geometry and operating effects when cutting small diameter holes in CFRP. Int J Mach Tool Manufact 2009; 49: 1008-1014.

16. Davim JP, Pedro R and António CC. Author links open the author workspace. b. Experimental study of drilling of glass fiber reinforced plastics (GFRP) manufactured by hand lay-up. Compos Sci Tech 2004; 64: 289-297.
17. Hocheng $\mathrm{H}$ and Tsao CC. Comprehensive analysis of delamination in drilling of composite materials with various drill bits. J Mater Process Tech 2003; 140: 335-339.

18. Tsao CC and Hocheng H. Taguchi analysis of delamination associated with various drill bits in drilling of composite material. Int J Mach Tool Manufact 2004; 44: 1085-1090.

19. Tsao $\mathrm{CC}$ and Hocheng $\mathrm{H}$. Computerized tomography and C-Scan for measuring delamination in the drilling of composite materials using various drills. Int J Mach Tool Manufact 2005; 45: 1282-1287.

20. Hocheng $\mathrm{H}$ and Tsao CC. Effects of special drill bits on drilling-induced delamination of composite materials. Int J Mach Tool Manufact 2006; 46: 1403-1416.

21. Faraz A, Biermann D and Weinert K. Cutting edge rounding: an innovative tool wear criterion in drilling CFRP composite laminates. Int J Mach Tool Manufact 2009; 49: 1185-1196.

22. Abrao AM, Rubio JCC, Faria PE, et al. The effect of cutting tool geometry on thrust force and delamination when drilling glass fibre reinforced plastic composite. Mater Des 2008; 29: 508-513.

23. Lazar MB and Xirouchakis P. Experimental analysis of drilling fiber reinforced composites. Int $J$ Mach Tool Manufact 2011; 51: 937-946.

24. Hocheng $\mathrm{H}$ and Tsao CC. Analysis of delamination in drilling composite materials using core drill. Australas $J$ Mech Eng 2003; 1: 49-53.

25. Tsao CC and Hocheng H. Effects of exit back-up on delamination in drilling composite materials using a saw drill and a core drill. Int J Mach Tool Manufact 2005; 45: 1261-1270.

26. Saleem M, et al. Role of the surface quality on the mechanical behavior of CFRP bolted composite joints. Int $J$ Fatig 2015; 80: 246-256.

27. Haddad M, Zitoune R and Bougherara H. Study of trimming damages of CFRP structures in function of the machining processes and their impact on the mechanical behavior. Compos B 2014; 57: 136-143.

28. Iliescu D, Gehin D, Gutierrez ME, et al. Modeling and tool wear in drilling of CFRP. Int J Mach Tool Manufact 2010; 50: 204-213.

29. Davim JP. Machining composite materials. New York: Nova Publishers, 2009.

30. Sheikh-Ahmad JY and Shinde SR. Machinability of carbon/epoxy composites by electrical discharge machining. Int J Mach Mach Mater 2016; 18: 3-17.

31. Krishnaraj V, Zitoune R and Davim JP. Drilling of polymer-matrix composites. Heidelberg: Springer, 2013.

32. Karimi NZ, et al. Analysis of damage mechanisms in drilling of composite materials by acoustic emission. Compos Struct 2015; 13: 107-114.

33. Hocheng $\mathrm{H}$ and Dharan CKH. Delamination during drilling in composite laminates. $J$ Eng Ind 1990; 112: 236-239.

34. Jain S and Yang DCH. Delamination-free drilling of composite laminates. J Eng Ind 1994; 116: 475-481.

35. Saoudi J, Zitoune R, Gururaja S, et al. Prediction of critical thrust force for exit-ply delamination during 
drilling composite laminates: thermo-mechanical analysis. Int J Mach Mach Mater 2016; 18: 77-98.

36. Saoudi J, et al. Critical thrust force predictions during drilling: analytical modeling and X-ray tomography quantification. Compos Struct 2016; 153: 886-894.

37. Feito N, Lopez-Puente J, Santiuste C, et al. Numerical prediction of delamination in CFRP drilling. Compos Struct 2014; 108: 677-683.

38. Hocheng $\mathrm{H}$ and Tsao CC. The path towards delamination-free drilling of composite materials. $J$ Mater Process Tech 2005; 167: 251-264.

39. Zhang LB, Wang LJ and Liu XY. A mechanical model for predicting critical thrust forces in drilling composite laminates. Proc Inst Mech Eng Part B J Eng Manuf 2001; 215: $135-146$.

40. Upadhyay P and Lyons J. On the evaluation of critical thrust for delamination-free drilling of composite laminates. J Reinf Plast Compos 1999; 18: 1287-1303.

41. Zitoune R and Collombet F. Numerical prediction of the thrust force responsible of delamination during the drilling of the long-fibre composite structures. Compos Part A Appl Sci Manuf 2007; 38: 858-866.

42. Gururaja S and Ramulu M. Modified exit-ply delamination model for drilling FRPs. J Compos Mater 2009; 43: 483-500.

43. Timoshenko S and Woinowsky-Krieger S. Theory of plates and shells. 2nd ed. New York: McGraw-Hill, 1959.

44. Collombet F, Mulle M, Grunevald Y, et al. Multiscale method for optimal design of composite structures incorporating sensors. Solid Mech Its Appl 2006; 135: 141-149.

\section{Appendix}

\section{Notation}

$a$ radius of the circular crack (mm)

$A$ area of the crack $\left(\mathrm{mm}^{2}\right)$

$c$ outer radius of the drill $(\mathrm{mm})$

$c^{*} \quad$ inner radius of the drill $(\mathrm{mm})$

$D$ bending rigidity of the plate (N.mm)

$D^{\prime} \quad$ stiffness coefficient (N.mm)

$D_{i j} \quad$ coefficients of bending stiffness matrix (N.mm)

$E$ Young's modulus for an isotropic material

$E_{l l}$ Young's modulus in the $\mathrm{L}$ direction $\left(\mathrm{N} / \mathrm{mm}^{2}\right)$
$E_{t t} \quad$ Young's modulus in the T direction $\left(\mathrm{N} / \mathrm{mm}^{2}\right)$

$F_{c} \quad$ critical thrust force for an isotropic material (N)

$F_{1}$ thrust force applied over a circular plate with diameter $\mathrm{c}(\mathrm{N})$

$F_{2}$ thrust force applied over a circular plate with diameter $c^{*}(\mathrm{~N})$

$F_{Z}$ global thrust force for an orthotropic material (N)

$F_{Z C}$ global critical thrust force for an orthotropic material $(\mathrm{N})$

$G_{I}$ strain energy release rate in mode $\mathrm{I}\left(\mathrm{J} / \mathrm{mm}^{2}\right)$

$G_{I c}$ critical strain energy release rate in mode I $\left(\mathrm{J} / \mathrm{mm}^{2}\right)$

$G_{I}^{1} \quad$ strain energy release rate in mode $\mathrm{I}\left(\mathrm{J} / \mathrm{mm}^{2}\right)$ of a plate with diameter $\mathrm{c}$

$G_{I}^{2} \quad$ strain energy release rate in mode $\mathrm{I}\left(\mathrm{J} / \mathrm{mm}^{2}\right)$ of a plate with diameter $\mathrm{c}^{*}$

$G_{l t}$ shear modulus $\left(\mathrm{N} / \mathrm{mm}^{2}\right)$

$h$ ply thickness $(\mathrm{mm})$

$H$ thickness of the plate

$k_{1}$ parameter relating to $\mathrm{F}_{\mathrm{Z}}$

$k_{2}$ parameter relating to $\mathrm{F}_{Z}$

$k_{3}$ parameter relating to $\mathrm{F}_{Z}$

$M \quad$ flexural rigidity of the plate (N.mm)

$q$ lateral uniform load $\left(\mathrm{N} / \mathrm{mm}^{2}\right)$

$q_{1} \quad$ lateral uniform load relating to $\mathrm{q}$

$q_{2}$ lateral uniform load relating to $\mathrm{q}$

$r$ radial coordinate $(\mathrm{mm})$

$s$ delamination ratio

$t$ thickness of the drill (mm)

$U$ global strain energy (N.mm)

$U_{1} \quad$ strain energy relating to $\mathrm{U}(\mathrm{N} . \mathrm{mm})$

$U_{2} \quad$ strain energy relating to $\mathrm{U}$ (N.mm)

$V_{f}$ fibre volume fraction (\%)

$W \quad$ work done by external forces (N.mm)

$W_{1}$ work of the external forces relating to $\mathrm{W}$ (N.mm)

$W_{2}$ work of the external forces relating to $\mathrm{W}$ (N.mm)

$\beta$ ratio between thickness and radius of core drill

$\theta$ polar coordinate

$v$ Poisson ratio for an isotropic material

$v_{l t} \quad$ Poisson ratio in (lt) direction 